\title{
Adoção e Preparação Infantil na Percepção dos Profissionais do Juizado da Infância e Juventude de Belém/PA
}

\author{
Suellen Reis Contente ${ }^{1}$ \\ Laboratório de Ecologia do Desenvolvimento da Universidade Federal do Pará, Belém, Brasil \\ Lilia Iêda Chaves Cavalcante \\ Instituto de Ciências Sociais Aplicadas da Universidade Federal do Pará, Belém, Brasil \\ Simone Souza da Costa Silva \\ Núcleo de Teoria e Pesquisa do Comportamento da Universidade Federal do Pará, \\ Belém, Brasil
}

\begin{abstract}
Resumo
O presente artigo discute como vem sendo desenvolvida e/ou como poderia ser realizada a preparação para adoção de crianças institucionalizadas na visão de analistas judiciários da $1^{\text {a }}$ Vara da Infância e Juventude de Belém. Participaram da pesquisa cinco assistentes sociais, duas psicólogas, duas pedagogas e uma socióloga. Os resultados obtidos por meio da aplicação de questionário mostraram que há consenso entre esses profissionais de que a preparação de crianças que vivem em instituições de acolhimento pode contribuir sob vários aspectos para que a adoção tenha êxito, particularmente ao prevenir ou minimizar o sentimento de medo diante da necessidade de se adaptar a um novo contexto familiar. Os participantes, em sua maioria, declararam até o momento não se sentirem capacitados para atuar na preparação de crianças como rege a Lei 12.010/2009. Alegam que a exigência legal da preparação infantil gerou uma demanda nova em termos profissionais, o que pode estar dificultando a elaboração de estratégicas metodológicas adequadas a um trabalho interdisciplinar com a atuação integrada de órgãos do judiciário e instituições de acolhimento. Nesta pesquisa, a preparação foi reconhecida como um conjugado de estratégias interventivas que deve permitir à criança visualizar por que e como seria seguro viver em outra família. Entre as mais citadas, além do trabalho em equipe interdisciplinar, a preparação concomitantemente de pais e filhos para adoção, o domínio de informações que os orientem nesse processo, e procedimentos que visam o envolvimento das crianças e suas histórias de vida de forma lúdica foram citadas frequentemente.
\end{abstract}

Palavras-chave: Adoção, criança institucionalizada, preparação para adoção.

\section{Adoption and Infantile Preparation in Perception of professional of Court of Childhood and Youth of Belém/PA}

\begin{abstract}
This article discusses how has been developed and / or how could been done to prepare for adoption of children institutionalized in legal analysts view the 1st Court of Childhood and Youth of Belém. Participants were five social workers, two psychologists, two educators and a sociologist. The results obtained by means of a questionnaire showed that there is consensus among the respondents that the preparation
\end{abstract}

Endereço para correspondência: Instituto de Ciências Sociais Aplicadas, Universidade Federal do Pará, Av. Augusto Correa, 01, Campus Universitário do Guamá, Guamá, Belém, PA, Brasil 66075-900. E-mail: suellencontente@hotmail.com, liliaccavalcante@gmail.com e symon.ufpa@gmail.com 
of children living in institutions can contribute in many ways to be successful adoption, particularly to prevent or minimize the feeling of fear due to the need to adapt to a new family context. The participants, mostly declared don 't feel qualified to act in the preparation of children as the law governing $12.010 / 2009$. They argue that the statutory requirement of preparing children generated a new demand in professional terms, which may be hindering the development of appropriate methodological strategy to interdisciplinary work with the integrated performance of the judiciary organs and host institutions. In this research, the preparation was recognized as a conjugate of interventional strategies that should allow the child to visualize why and how it would be safe to live in another family. Among the most frequently cited responses, in addition to interdisciplinary teamwork, preparation concomitantly of parents and children for adoption, the domain of information to guide them in this process, and procedures aimed at the involvement of children and their life stories through play.

Keywords: Adoption, child institutionalized, preparation for adoption.

\section{Preparación y Adopción de Niños en la Percepción de los Profesionales Judicatura para los Niños y Jóvenes Belém/PA}

\section{Resumen}

En este artículo se analiza cómo se ha desarrollado y / o cómo se puede hacer para prepararse para la adopción de niños institucionalizados según los analistas jurídicos de la Judicatura para los Niños y Jóvenes Belém/PA. Los participantes fueron cinco trabajadores sociales, dos psicólogos, dos educadores y un sociólogo. Los resultados obtenidos por medio de un cuestionario mostró que hay consenso entre los encuestados de que la preparación de los niños que viven en instituciones residenciales pueden contribuir de muchas maneras a ser exitosa adopción, en particular para evitar o reducir al mínimo la sensación de miedo que enfrentan a la necesidad de adaptarse a un nuevo contexto familiar. Los participantes, en su mayoría reportado hasta la fecha no se siente calificado para actuar en la preparación de los niños como la ley 12.010/2009. Afirman que el requisito legal de preparar a los niños genera una nueva demanda en términos profesionales, que pueden estar obstaculizando el desarrollo de la estrategia metodológica adecuada para el trabajo interdisciplinario con la actuación integrada de los órganos judiciales y las instituciones de acogida. En esta investigación, la preparación ha sido reconocido como un conjugado de estrategias de intervención que deberían permitir al niño a ver por qué y cómo sería seguro vivir con otra familia. Entre las estratégias de preparación más citadas, además de trabajo en equipo interdisciplinario, concomitantemente con los padres y niños para la adopción, el dominio de la información que los guíe en este proceso, y procedimientos dirigidos a la participación de niños y sus historias de vida a través del juego.

Palabras clave: Adopción, niños institucionalizados, la preparación para la adopción.

A adoção se constitui em uma medida de proteção especial que tem como principal objetivo dar às crianças que se encontram em acolhimento institucional o direito de viver em família e construir novos vínculos socioafetivos. Esta medida, contudo, requer a preparação de pais e filhos pela própria natureza da experiência a ser vivenciada, uma vez que a adoção implica, sobretudo, em um processo longo e progressivo de adaptação da criança ao convívio com a nova família. Sabe-se hoje que, quando se adota al- guém, se acolhe também a sua história de vida, inclusive as marcas deixadas por sua contínua exposição a situações de risco em contextos primários anteriores (Gueiros, 2007).

Estudos disponíveis na literatura (Centro de Capacitação e Incentivo à Formação de Profissionais, Voluntários e Organização que Desenvolvem Trabalho de Apoio à Convivência Familiar [CeCIF], 2002; Figueiredo, 2010; Motta, 2008; Solon, 2008; Weber, 2001, 2010) têm indicado uma clara associação do termo prepa- 
ração à atitude que equivale a informar, levar conhecimento, esclarecer, desmistificar, revelar os mitos e preconceitos que cercam o tema da adoção e dar condições para que a criança possa ter êxito nesse enfrentamento. Nesse sentido, preparar a criança para a vida em um lar adotivo é dotá-la de conhecimentos apurados sobre essa nova forma de se viver em família (Andrade, Costa, \& Rossetti-Ferreira, 2006) e a oportunidade colocada de nesse contexto construir laços familiares não consanguíneos (Mariano \& Rossetti-Ferreira, 2008). A importância do conhecimento prévio sobre a natureza dessa vinculação pode ser explicada, assim, pelo fato de que, na sociedade ocidental, a ligação hereditária historicamente é vista como um desígnio indiscutível que dita normas de valorização e continuidade familiar e percebe a adoção como algo inautêntico e artificial (Costa \& Campos, 2003). Esta compreensão pode dificultar o processo de construção de vínculos afetivos, o que torna essencial, desse ponto de vista, a preparação da criança para a adoção e a vivência de um período que tem como marca a transitoriedade (Cavalcante \& Magalhães, 2012).

Quando o processo de acolhimento ocorre por tempo demasiadamente longo, ou seja, em um período superior a dois anos, estudos (Cavalcante \& Magalhães, 2012; Solon, 2008) apontam que a possibilidade de construção de novos vínculos socioafetivos pela criança deve ser vista como uma experiência potencialmente positiva. Nesses termos, a preparação para a adoção é entendida como uma medida ainda mais indicada, sobretudo dada à complexidade das demandas infantis envolvidas no processo de transição da criança de um ambiente tipicamente institucional para outro de configuração familiar, mas que a princípio the parece completamente estranho (Cavalcante \& Magalhães, 2012). Cada alteração vivida pela criança nessa condição específica faz parte de um conjunto de transições que está em curso, que provoca expectativa de mudanças intensas, assim como invoca sofrimentos e perdas passadas, construindo habilidades para que possa figurar como protagonista de sua própria história (Motta, 2008; Solon, 2008; Weber, 2010).

Ao se deparar com a necessidade da construção de novos vínculos socioafetivos, a litera- tura mostra que crianças institucionalizadas que não foram sistematicamente orientadas durante $o$ período de transição para a nova família poderão oferecer resistência no decorrer do processo de adaptação ou sentir medo diante de um ambiente acerca do qual não dispõem de informações precisas sobre suas características (Mariano \& Rossetti-Ferreira, 2008).

Em qualquer circunstância, dar às crianças institucionalizadas informações acerca de sua futura família é uma forma de dotá-las de conhecimentos que poderão prepará-las para as novas exigências de adaptação que certamente encontrarão pela frente e o reconhecimento dos vínculos que fazem a ligação entre os contextos envolvidos nesse processo transitório. Entretanto, no caso das crianças que se encontram em acolhimento institucional, admite-se que a preparação para adoção assume diferentes contornos, tornando-se mesmo indispensável (Ayres, Cardoso, \& Pereira, 2009; Beckett et al., 2006; Solon, 2008; Weber, 2010).

Em razão disso, o motivo do fracasso associado a algumas adoções tem sido atribuído à ausência de um trabalho multiprofissional especialmente voltado a crianças institucionalizadas que estejam disponíveis para a adoção (Gueiros, 2007; Kramer, Barbosa, \& Silva, 2008; Solon, 2008; Weber, 2010). Esses autores vêm mostrar que a preparação das crianças não ocorre da mesma forma como se dá comumente essa experiência com os pais adotivos, nem parece despertar preocupação semelhante nos profissionais da área sociojurídica.

Nesse sentido, Weber (2001) afirma existir um grande número de pesquisas que tem se dedicado a investigar a preparação dos pais para adoção e a escassez de estudos que procuram compreender o trabalho de orientação e apoio às crianças nessa importante transição de um ambiente que se difere física e socialmente. A autora reconhece ser evidente a importância do apoio e a necessidade de orientação aos pais nesse processo de inserção e adaptação da criança ao novo ambiente, porém, considera que igual atenção deveria ser dada à preparação infantil para a adoção, sobretudo quando esta se encontra em situação de acolhimento institucional prolongado (Serrano, 2008; Weber, 2010). 
É importante ressaltar que, na verdade, a pouca ou nenhuma atenção conferida à preparação para adoção de crianças desde os primeiros anos de vida deita suas raízes históricas nos primórdios de uma sociedade que sempre atribuiu maior poder à posição ocupada pelo adulto, sobretudo quando este está imbuído do papel parental (Costa \& Campos, 2003; Figueiredo, 2010; Solon, 2008). Em outras palavras, a adoção por muito tempo se constituiu em uma medida voltada à satisfação daqueles que têm o desejo de construir uma família, mas que encontram dificuldades de gerar filhos de modo natural, sendo esperado que este seja o argumento que em geral justifica tal decisão, como assinala Pontes, Cabrera, Ferreira e Vaisberg (2008):

De fato, a adoção aparece como alternativa última para a realização do desejo de maternidade e paternidade, após várias tentativas frustradas de gestação. Assim se configura em uma ótica bastante individualista, como solução para os problemas do casal, sem levar em conta os carecimentos da criança (p. 499).

Dessa forma, a concepção centrada no bem estar da criança ao longo da história esteve presente de forma periférica, o que fez com que ocorresse uma sobreposição dos desejos e anseios do adotante sobre os do adotado. Esta posição de destaque ocupada hoje pela criança é, portanto, recente, ainda que a prática da adoção seja secular. Weber (2010) enfatiza que, na sociedade brasileira, a decisão de adotar sempre esteve ancorada no interesse da família, sendo possível perceber que geralmente o adotado não tem voz nem participação nesse processo. Nos dias atuais, em que pesam os nítidos avanços na forma de se perceber a adoção e a necessidade de preparar e integrar os sujeitos desse processo (Mariano \& Rossetti-Ferreira, 2008) ainda é possível notar os reflexos dessa antiga cultura na prática de sobrepor os interesses do adotante ao do adotado. Pontes et al. (2008) lembram que a esterilidade do casal e a necessidade de continuação dos laços não consanguíneos foram interpretados como interesses unilaterais, isto é, que tomam somente a perspectiva dos anseios e necessidades de quem não pode ou não quer gerar filhos biológicos.
Apesar das conquistas e evoluções em relação ao estabelecimento da adoção como medida de proteção especial à criança que deve valorizar a sua participação nesse processo, apontadas inicialmente nos Códigos de Menores de 1927 e 1979, mas apenas consolidadas com o Estatuto da Criança e do Adolescente - ECA (Lei ${ }^{\circ}$ 8.069, de 13 de julho de 1990), e a Lei Nacional da Adoção (Lei n ${ }^{\circ}$ 12.010/2009, de 3 de agosto de 2009), observa-se que a preparação das crianças para adoção ainda permanece em segundo plano. A legislação mais recente ressalta o lugar destacado da preparação no curso da adoção, contudo chama atenção para a condição em que este procedimento deverá ser realizado com crianças e adolescentes, posto que este requer o acompanhamento sistemático e competente por parte de profissionais e autoridades que atuam no âmbito da Justiça da Infância e Juventude, como define um de seus artigos.

$\S 50$ A colocação da criança ou adolescente em família substituta será precedida de sua preparação gradativa e acompanhamento posterior, realizados pela equipe interprofissional a serviço da Justiça da Infância e da Juventude, preferencialmente com o apoio dos técnicos responsáveis pela execução da política municipal de garantia do direito à convivência familiar.

Com a Lei $n^{\circ} 12.010 / 2009$, passa a ser obrigatória a preparação de crianças que vivem em instituições de acolhimento para a convivência em família substituta. As mudanças no marco regulatório e nas políticas pelo direito à convivência familiar e comunitária refletem a percepção cada vez mais atual de que é importante ouvir as crianças sobre suas necessidades, interesses e preferências (CeCIF, 2002; Figueiredo, 2010; Motta, 2008; Solon, 2008; Weber, 2010). Nos casos de adoção tardia que envolve crianças com mais de dois anos de idade, há o entendimento de que a sua voz deve ser ouvida e sua vontade considerada por profissionais com formação em diferentes áreas, como Psicologia, Serviço Social, Pedagogia, Sociologia e outras afins.

Solon (2008), ao dialogar com crianças sobre o significado de adotar alguém, verificou que para elas a adoção estava relacionada à conduta infantil. Os participantes da pesquisa associa- 
vam o significado da adoção, ora à recompensa pela boa conduta infantil, ora à punição pelo mau comportamento da criança no contexto da instituição de acolhimento. Entre as crianças entrevistadas pela pesquisadora, a adoção muitas vezes foi apresentada como dependente do comportamento infantil, associada à presença de condutas socialmente adequadas ou não.

A partir dos resultados obtidos por Solon (2008), conclui-se que essa ambivalência presente na visão dos participantes acerca da adoção se revela especialmente entre crianças que sofreram alguma forma de privação afetiva, seja porque foram abandonadas e/ou negligenciadas por sua família de origem, seja porque temem a possibilidade de virem a ser rejeitadas pelos pais adotivos. Por isso, segundo os preceitos contidos na Lei $\mathrm{n}^{\circ} 12.010 / 2009$, as crianças devem ser informadas e estimuladas a reconhecer a adoção como uma medida social que visa garantir o direito fundamental à convivência familiar e comunitária, não devendo estar associada ou, muito menos, condicionada, ao padrão de comportamento presente no espaço de acolhimento infantil.

A preparação para as crianças tem sido enfatizada e percebida como indispensável diante de casos em que foram detectados graves equívocos e frustrações no processo de adaptação da criança à família substituta, como argumentara Weber (2010). A justificativa para um investimento maior na preparação infantil tem sido respalda por situações que estão se tornando comuns como a devolução de crianças após breve ou longo período de convivência com a família adotante e a tão propalada falta de diálogo com o adotando. A análise da condição psicossocial da criança que estando há anos em uma instituição passa a ter que conviver e se adaptar à vida em uma família substituta, tem provocado a necessidade de se conhecer e trabalhar mais seus medos, seus anseios, sua trajetória e perspectiva de vida.

Apesar dos fatores que justificam a necessidade de preparação da criança para adoção terem sido abordados pela literatura mais recente no Brasil (CeCIF, 2002; Figueiredo, 2010; Gueiros, 2007; Motta, 2008; Solon, 2008; Weber, 2001, 2010), e também em produções internacionais (McGuire \& Shanahan, 2010) questões que dizem a respeito aos propósitos dessa forma particular de lidar com o adotando e como este trabalho vem sendo realizado no Brasil, deixa evidente a falta de interesse acadêmico pelo tema. Provavelmente a dificuldade em abordar teórica e metodologicamente tal questão, sem vieses ideológicos ou interpretações subjetivistas, deva ser apontada como um dos fatores que tem contribuído para a existência de uma produção ainda pouco expressiva sobre o tema diante da sua urgência e complexidade na atualidade.

Para Weber (2010), nesse contexto específico, preparar envolve tanto o compromisso de fornecer informações sobre a criança para os futuros pais adotivos, quanto a disposição para apresentar ao adotante uma descrição fidedigna de características e fatos relativos à sua nova família, por meio de fotos, vídeos, além de esclarecimentos diversos quanto à casa em que irá morar, o convívio com irmãos, dentre outros. $\mathrm{Na}$ preparação para a adoção, desmistificar e esclarecer implica no cuidado e respeito à vida pregressa da criança e não na sua ocultação e/ ou deturpação. Ou seja, a preparação deve evitar separar a criança do seu passado e soterrar a sua identidade por meio da divulgação de informações vagas e dispersas, seja na família de origem ou na instituição onde foi acolhida como medida de proteção social.

Por isso, entre várias medidas, este dentre outros estudos (Gueiros, 2007; Motta, 2008; Solon, 2008; Weber, 2001, 2010), considera que deve ser permitido à criança trazer parte dos seus pertences para a nova vida, inclusive fotos e/ou objetos que remetem ao convívio nos ambientes anteriores que lhe trazem algum conforto emocional. Esses estudos recomendam que deva ser respeitado o tempo que a criança precisa para viver com segurança a passagem que lhe fará transitar de um ambiente tipicamente institucional para o convívio em um meio familiar, porém completamente estranho a ela.

. . com aproximações sucessivas, pode-se chegar a uma conciliação da família sonhada com a família possível e desenvolve na criança uma noção do que ela pode encontrar (alegrias e dificuldades) neste processo de inserção social. Tendo o suporte necessário, uma ponte segura, elas estarão melhor 
instrumentalizadas para fazer a sua travessia do abandono/instituição para o seio de uma família. (Weber, 2010, p. 224)

Igualmente, para Solon (2008), o argumento usado para validar a importância da preparação está sustentado na ideia de que a criança precisa ter previamente uma imagem completa de sua vida e o maior entendimento possível de que sua história começou antes da adoção. Em razão disso, a autora incentiva a construção com a criança de um livro, uma espécie de álbum de fotografias e desenhos, que exiba comentários reflexivos sobre a decisão de adotar, colocando em relevo as razões e a forma como se deu a escolha da criança (por exemplo, utilizar frases como "Eu fui buscar você...").

Por sua vez, na publicação 101 Perguntas e Respostas sobre Abandono e Institucionalização (CeCIF, 2002) há a consideração de que a preparação das crianças tem início com o trabalho de integração entre os abrigos e os juizados responsáveis pelo andamento do processo jurídico, que vai desde a destituição do poder familiar até a sentença da adoção, devendo ser esta experiência discutida por diferentes equipes de trabalho e autoridades competentes em cada instância legalmente envolvida. Hoje, conforme a Lei $n^{\circ}$ $12.010 / 2009$, esta visão de trabalho integrado está em fase de consolidação na área da defesa sociojurídica dos direitos da criança e do adolescente. Nela, está claro que a preparação para adoção não é atribuição exclusiva da equipe técnica da Justiça da Infância e da Juventude, apesar de que obrigatoriamente deve ser envolvida neste trabalho, mas requer antes de tudo a participação de profissionais responsáveis pela execução das Orientações Técnicas para Serviços de Acolhimento de Crianças e Adolescentes (Ministério do Desenvolvimento Social e Combate à Fome [MDS], 2009) e do Plano Nacional de Promoção, Proteção e Defesa do Direito da Criança e do Adolescente à Convivência Familiar e Comunitária (MDS, 2006), que estabelecem que as condições para viver em família de forma saudável e segura é um direito fundamental e que este deve ser o princípio que orienta as políticas municipais e estaduais na contemporaneidade.

Outro aspecto a ser observado na discussão sobre por que e como proceder à preparação para a adoção, deixa claro que o seu êxito depende da idade da criança no momento em que viverá tal experiência. Pontes et al. (2008) consideram que "muitas crianças abrigadas, com mais de dois anos de idade, já têm compreensão suficiente para nutrir expectativas ansiosas de serem escolhidas e acolhidas por casais interessados" (p. 496). Há de se considerar, contudo, que nem todas as crianças apresentam o mesmo nível de compreensão sobre o que é adoção por se encontrarem em idades distintas, sendo importante observar o peso dessa variável na decisão do que deve ser informado e a forma como esse trabalho pode ser realizado diante das particularidades que caracterizam os casos atendidos. Conversas sobre a perspectiva colocada pela vida em uma nova família, a oferta de informações quanto à identidade e a condição de vida dos pais adotivos, a troca de fotografias entre as pessoas envolvidas, a facilitação do contato entre elas, são exemplos de procedimentos apontados em estudos (Costa $\&$ Campos, 2003) que podem envolver a criança, mas de acordo com a idade que possui e o nível de maturidade que lhe é correspondente.

Estudos recentes (Gueiros 2007; Solon 2008; Weber, 2001) mostram que essa aproximação precisa ser gradativa e consentida pela criança e pelos pretendentes à adoção, exigindo de profissionais e autoridades a capacidade de avaliar de que forma a preparação infantil será mais benéfica: com ou sem a oportunidade de um contato prévio e íntimo com a família com a qual será levada a conviver; com ou sem a permissão para passeios e convivência diária que culminem com a ida definitiva para a casa dos adotantes.

Para muitos juízes, segundo Figueiredo (2010), a preparação prévia é absolutamente indispensável, de modo que a criança/adolescente gradativamente vai aceitando a nova situação e se incluindo, por vontade própria, na nova família. Em posição oposta, o autor descreve aqueles que defendem o imediato desligamento da instituição acolhedora e sua inserção direta na família substituta. Aponta que é extremamente difícil para a criança elaborar a ideia de que está diante daqueles que serão seus pais, seus irmãos, seus avós. Essa compreensão inicial pode facilitar ou dificultar a formação de laços afetivos da criança com os membros de sua nova família, 
principalmente porque em geral teme que ocorra uma nova rejeição ou abandono como o que fora vivenciado no passado.

Embora seja hoje indiscutível a importância da preparação infantil, Figueiredo (2010) argumenta que se deve ponderar a entrega antecipada à criança de fotos, filmagens, cartas, além da sua prolongada exposição aos comentários de terceiros (geralmente, técnicos e outros funcionários das instituições de acolhimento) sobre a futura família. Para o autor, estas são medidas que contribuem eficazmente não apenas para a conclusão do processo da adoção, mas principalmente com a fase que a antecede e que corresponde ao estágio de convivência familiar. Essa é a fase que marca o início da preparação da criança propriamente dita e por isso deve ser vista como fundamental. É nesse momento que se dá a criação das condições adequadas para a realização do estágio de convivência com a família, que, por sua vez, poderá favorecer ou não a própria conclusão do processo de adoção.

Diante do debate que permeia a literatura disponível sobre o tema e a demanda posta por novas investigações e proposições, considera-se que o objetivo do presente estudo consiste em analisar como tem sido e/ou como poderia ser realizada a preparação de crianças institucionalizadas para a adoção na percepção dos analistas judiciários da $1^{\text {a }}$ Vara da Infância e Juventude de Belém.

\section{Método}

\section{Participantes}

A pesquisa foi realizada na $1^{\text {a }}$ Vara da Infância e Juventude da Comarca da Capital, em Belém do Pará, que se dedica à proteção dos direitos coletivos, difusos e Meta individuais envolvendo questões de proteção de crianças e adolescentes em situação de risco, particularmente os casos que demandam atendimento sociopsicopedagógico (principalmente os que se encontram em serviços de acolhimento institucional) e a resolução de conflitos de interesses e definição de sentença de guarda, tutela e adoção.

Participaram da pesquisa membros que integram a equipe multiprofissional responsável por auxiliar e subsidiar as decisões judiciais na perspectiva da garantia dos direitos da criança e do adolescente, e de suas famílias. Pela natureza do trabalho realizado, observa-se a atuação interdisciplinar dos chamados analistas judiciários, dentre os quais figuram assistente sociais, psicólogos, sociólogos e pedagogos. Dos 15 profissionais com presença na instituição, concordaram em tomar parte da pesquisa 10 deles, sendo todos do sexo feminino, com pelo menos 04 a 29 anos na função e idades que variaram de 29 a 61 anos, com terceiro grau completo e alguns com curso de pós-graduação. A Tabela 1 assinala estas informações:

\section{Tabela 1}

Perfil dos Participantes da Pesquisa

\begin{tabular}{lcccc}
\hline Nome & Sexo & Idade & Escolaridade & Tempo de serviço \\
\hline Pedagoga A & Feminino & 29 & Mestrado & 04 anos e 3 meses \\
Pedagoga B & Feminino & 53 & Graduação & 30 anos \\
Socióloga A & Feminino & 59 & Graduação & 28 anos \\
Assistente Social A & Feminino & 51 & Graduação & 27 anos e 08 meses \\
Assistente social B & Feminino & 44 & Especialização & 03 anos e 06 meses \\
Assistente Social C & Feminino & 39 & Especialização & 03 anos e 06 meses \\
Assistente Social D & Feminino & 44 & Mestrado & 20 anos \\
Assistente Social E & Feminino & 61 & Graduação & 29 anos e 07 meses \\
Psicóloga A & Feminino & 50 & Graduação & 29 anos e 08 meses \\
Psicóloga B & Feminino & 30 & Mestrado & 04 anos e 02 meses \\
\hline
\end{tabular}




\section{Instrumento}

O instrumento utilizado na coleta de dados foi um questionário contendo dez itens, sendo sete perguntas abertas e três fechadas. As questões que compunham o instrumento foram assim organizadas: (a) Dados do participante (sexo, idade, estado civil, escolaridade, tempo de serviço na instituição); (b) Definição de adoção; (c) Aspectos da preparação para adoção (O que entende como preparação para adoção? É possível haver preparação para adoção? Se sim, você a considera necessária? A instituição em que você trabalha realiza a preparação de crianças para adoção? Em caso positivo, discorra como se dá esse processo. Em caso negativo, explique por que esse processo não faz parte da rotina da instituição. Qual a sua opinião sobre o modo como as crianças tem sido preparadas para adoção na instituição em que você trabalha? Como essa preparação poderia ser realizada? Há algum tipo de investimento na capacitação dos técnicos para a preparação de crianças à adoção? Em caso positivo, de que forma são capacitados para a preparação de crianças para adoção? Com o estabelecimento da Lei $\mathrm{n}^{\circ} 12.010 / 2009$, você considera que houve mudanças no modo como é realizada a preparação de crianças para adoção? Quais são as principais dificuldades apresentadas no processo de preparação dessas crianças para adoção? Como você entende a preparação de pais pretendentes à adoção? Qual a sua opinião sobre o modo como os pais têm sido preparados para adoção na instituição em que você trabalha? Como essa preparação poderia ser realizada? Quais as semelhanças e diferenças entre a preparação de crianças institucionalizadas e não institucionalizadas?).

\section{Coleta de Dados}

Como parte dos procedimentos iniciais da pesquisa, foram tomadas as providências para a autorização da pesquisa com os profissionais vinculados à instituição. Como esta proposta de estudo era parte de um projeto já submetido à apreciação do Comitê de Ética em Pesquisa envolvendo Seres Humanos do Núcleo de Medicina Tropical, que teve a sua realização aprovada sob o protocolo $n^{0}$ 018/2008 - CEP/MMT foi feito contato pessoal com cada um dos profissionais com atuação na instituição. Dos 15 profissionais que foram abordados, dez aceitaram preencher o questionário e concordaram em devolvê-los após duas semanas. $\mathrm{O}$ período destinado à coleta dos dados se estendeu de janeiro a março de 2011.

\section{Análise dos Dados}

Para a organização e tratamento dos dados, utilizou-se categorias que haviam sido definidas a partir da análise do conteúdo das respostas dadas pelas participantes a cada uma das questões trazidas pelo questionário. Com as categorias mais aludidas, houve a definição em organizar e elencar o que havia sido mais destacado durante as analises realizadas a luz das respostas dos sujeitos. Para a discussão foram considerados conceitos e proposições extraídos da literatura que trata da preparação de crianças para adoção (Figueiredo, 2010; Gueiros, 2007; Motta, 2008; Solon, 2008; Weber, 2001, 2010).

\section{Resultados e Discussão}

Os resultados serão apresentados e discutidos com base em três categorias e subcategorias:

1. A realização do trabalho de preparação de crianças institucionalizadas para adoção.

2. O entendimento dos profissionais sobre o significado da preparação de crianças (orientação e esclarecimento sobre adoção, desconstrução de mitos sobre adoção, produto do trabalho envolvendo adotados e adotandos, trabalho interdisciplinar).

3. Propostas para a preparação infantil (diálogo entre a equipe dos abrigos e a equipe do Juizado, acompanhamento psicológico para as crianças, percepção das crianças e reflexões sobre a família adotiva).

\section{A Realização do Trabalho de Preparação de Crianças Institucionalizadas para Adoção}

Inicialmente, ao se questionar a realização da preparação de crianças institucionalizadas para a adoção no âmbito da $1^{\text {a }}$ Vara da Infância e Juventude da Comarca da Capital, verificou-se que não há consenso sobre isso entre os dez pro- 
fissionais que participaram da pesquisa, uma vez que cinco afirmaram e outros cinco negaram a existência desse tipo de trabalho.

Os dados que permitiram confirmar a realização da preparação para adoção estão associados ao acompanhamento dos processos de adoção realizados de forma sistemática pelos profissionais responsáveis pelos casos, o estreitamento do relacionamento que estes normalmente estabelecem com os futuros pais, à realização de estudos técnicos que relatam a trajetória da criança, a sua história de vida e, por fim, à utilização de instrumentos lúdicos com finalidade de intervenção que trabalhe melhor as dúvidas e os questionamentos surgidas no processo, como mostra o trecho da resposta dada por uma das participantes:

A meu ver a preparação ocorre a partir do estudo social quando se inicia o contato da equipe técnica com os pretendentes pais e oportunamente já de reduzirem diversas reflexões. Porém, o momento de maior aprofundamento se dá quando a realização do curso reúne diversos pretendentes, cuja metodologia é bastante dinâmica, procurando fomentar a troca de experiências. Além disso, outro momento é quando chega o momento do casal de receber a criança, pois a equipe de referência iniciará o acompanhamento procurando estabelecer a aproximação de futuros pais e filhos, tudo em parceria com a equipe técnica do espaço de acolhimento (Pedagoga B, 53 anos).

Conforme foi informado pelos participantes, em um primeiro momento, a preparação se dá por meio da aproximação gradual da criança com a família que no futuro a acolherá, já, no momento seguinte, esse processo de conhecimento prévio vai se estabelecendo mais e mais na medida em que os adotantes são informados de fatos que marcam a sua vida pregressa e a sua condição atual. É nessa ocasião que os profissionais costumam lembrar aos adotantes que a criança pretendida já tem uma história de vida, ou seja, como pai adotivo terá que saber lidar com o fato de que o filho que carrega nos braços traz consigo as marcas deixadas por situações emocionalmente negativas decorrentes de razões diversas (Fonsêca, Santos, \& Dias, 2009), tendo sido não raras vezes privado dos cuidados adequados na família (Zeanah, Smyke, \& Koga, 2005).

Do ponto de vista da criança, os participantes consideram que por sua própria condição etária tende a não possuir clareza de todas as questões implicadas na experiência da adoção, nem ter a noção exata das limitações que o convívio em família multiproblemática pode oferecer à sua segurança física e emocional. Tal qual foi discutido a partir de autores como Motta (2008), Solon (2008) e Weber (2001, 2010), a criança não pode ser separada brutalmente do seu passado, pois antes mesmo de ser adotada já tinha uma vida, sua existência, que não começa a se desenrolar com o processo de adoção. A continuidade entre o passado e o ingresso da criança em uma família adotiva pode ser mantida através de oportunidades colocadas para que ela "possa explorar sua história através de conversas, jogos e narrativas" (Solon, 2008, p. 20).

Conversar sobre a adoção com as crianças é um dos meios de se evitar situações que possam produzir comportamentos de desobediência, de desafios da autoridade dos pais que podem ser comuns nestas situações. Para Weber (2010), este comportamento infantil se justifica, uma vez que sua história pessoal lhe ensinou a desconfiar das pessoas e também lhe apresentou o caminho da rebeldia e da agressividade como estratégia para interagir socialmente.

Entre os profissionais que afirmaram não existir na instituição onde atuam este trabalho de preparação da criança para a adoção, justificaram sua resposta destacando os seguintes pontos:

1. O contato e a convivência com a criança nos abrigos confere aos técnicos dos espaços de acolhimento a possibilidade de desenvolverem melhor esse tipo de trabalho.

2. Historicamente, esta tem sido uma atribuição quase que exclusiva dos profissionais que atuam nos espaços de acolhimento institucional.

3. Este procedimento é parte de uma política nova e obrigatória, estando o corpo técnico ainda em uma fase em que eles próprios precisam ser preparados para saber lidar com as exigências teóricas e metodológicas por um tipo de trabalho que tem necessariamente 
caráter interdisciplinar e prevê a integração de serviços em rede. $\mathrm{O}$ depoimento a seguir ilustra a extensão das preocupações colocadas aos profissionais que são legalmente responsáveis por essa forma específica de atuação junto a adotantes e adotados:

"A preparação de crianças para adoção a ser realizada por técnicos da Vara da Infância e Juventude e dos abrigos passou a ser obrigatória com a Lei 12.010 /2009, porém historicamente tal preparação sempre foi atribuição da equipe interdisciplinar das entidades de acolhimento. No entanto a equipe interdisciplinar da Vara deverá realizar as adequações necessárias para que a lei possa ser cumprida" (Assistente Social B, 44 anos).

Em consonância com (Figueiredo, 2010; Gueiros, 2007; Motta, 2008; Solon, 2008; Weber, 2001, 2010), compreende-se que a Lei de Adoção $n^{\circ}$ 12.010/2009 é um instrumento jurídico novo e sua aplicação por ser obrigatória tem gerado controvérsias e inquietações quanto a melhor forma de assegurar todos os dispositivos implicados. Entretanto, as consequências da ausência da preparação infantil para adoção não são propriamente inéditas e sempre se tornaram mais visíveis quando há devolução de crianças por parte de adotantes no período do estágio de convivência familiar ou quando até a conclusão do processo judicial não se adaptaram, como o esperado, ao novo ambiente familiar. A Lei de Adoção no 12.010/2009 é bem clara e objetiva ao abordar a necessidade da preparação da criança para adoção, no entanto, muitos dos seus defensores consideram que ainda será preciso algum tempo até que sejam feitas as adequações necessárias para que as instituições e os profissionais envolvidos consigam contemplar as demandas geradas por anos de um trabalho importante, mas que era realizado muitas vezes de forma casual e desprovida de fundamentos teórico-metodológicos, tal como observaram (Figueiredo, 2010; Gueiros, 2007; Motta, 2008; Solon, 2008; Weber, 2001, 2010).

Nesse sentido, para aqueles participantes que consideraram que a preparação infantil não é realizada na esfera do judiciário, fica evidente que agora será necessário buscar meios de tor- ná-la concreta e isso será um contínuo desafio para toda a equipe. Para aqueles profissionais que avaliaram que a preparação de crianças institucionalizadas para a vivência da adoção já é uma realidade na instituição pesquisada, trata-se então de apoiar o trabalho proposto em metodologias que possam aperfeiçoa-lo e tornar a sua ação mais eficaz, sendo esta uma tarefa que vai exigir o envolvimento de todos, independente de sua formação acadêmica e área de atuação.

A questão sobre se houve ou não mudanças introduzidas com a Lei $\mathrm{n}^{\circ}$ 12.010/2009 no quesito preparação para adoção de crianças, pretendeu deixar claro se no entendimento dos participantes houve efetivamente alguma modificação neste aspecto. Dentre os dez profissionais que responderam à pergunta, seis afirmaram que houve mudanças e quatro alegaram que não houve. Os que alegaram que houve mudança na forma como o trabalho era realizado até então com crianças institucionalizadas que estavam disponíveis para a adoção, consideram que a Lei ${ }^{\circ} 12.010 / 2009$ inovou ao tornar esse tipo de trabalho que é uma responsabilidade conjunta dos analistas judiciários e técnicos dos espaços de acolhimento institucional. Antes, as respostas a essa preparação eram dadas somente pelos abrigos infantis, tornando-se agora uma responsabilidade também da $1^{\text {a }}$ Vara da Infância e Juventude de Belém. A seguir, tem-se o trecho da avaliação feita por um dos profissionais participantes da pesquisa que deixa claro esse ponto de vista.

"Sim, houve particularmente uma alteração formal que coloca essa preparação sob a responsabilidade da Vara da Infância e Juventude, qual preferencialmente deverá somar juntos aos abrigos. Embora a preparação já ocorresse, a formalização da função da Vara da Infância e Juventude exigiu o estabelecimento de um protocolo mínimo para tal preparação considerando desde o $1^{\circ}$ contato com o abrigo até o periodo de aproximação da criança ou adolescente com a familia pretendente a adotá-lo" (Pedagoga A, 29 anos).

Entre os entrevistados que disseram que não houve mudanças, há o reconhecimento de que a Lei $\mathrm{n}^{\circ}$ 12.010/2009 tornou obrigatório o trabalho da preparação. Contudo, enfatizaram que para 
haver mudanças efetivas deve existir um trabalho interdisciplinar, o que implica na elaboração de uma metodologia e um tipo de planejamento que reúnam conhecimentos e gerem interfaces entre diferentes olhares sob uma mesma questão. Esta perspectiva encontra apoio nas reflexões trazidas por Solon (2008), ao comentar que a mudança gerada pela obrigatoriedade da preparação infantil nos processos de adoção ainda não está em curso, sendo esperado que leve algum tempo até que possa ser percebida na forma e no ritmo estabelecidos na forma da lei. No presente estudo, um trecho ilustra essa estimativa.

“. . . isso ainda não está ocorrendo porque as crianças e adolescentes estão nos abrigos e vamos esbarrar em problemas materiais, estruturais, administrativos, gestão de pessoas ..." (Assistente Social E, 61 anos).

\section{O Entendimento dos Profissionais sobre o Significado da Preparação de Crianças}

Sobre o significado da preparação da criança para a adoção, os dados dos questionários aplicados foram organizados em torno de quatro subcategorias, estando entre as mais citadas: orientação e esclarecimento sobre o tema da adoção; desconstrução de mitos sobre a adoção; produto de um trabalho que envolve o adotado e o adotando; trabalho interdisciplinar que requer a atuação conjunta das equipes de técnicos do judiciário e dos espaços institucionais que acompanham os processos de adoção.

Orientação e Esclarecimento sobre o Tema da Adoção. Dentre os dez profissionais que contribuíram com a pesquisa, sete consideraram que a preparação pode ser definida como orientação, esclarecimento sobre o que é adoção e como funciona, mas também remete à importância de se tornar mais claro o perfil das crianças que estão vivendo nos espaços de acolhimento institucional e as implicações em termos teóricos e práticos. Em função disso, uma das participantes da pesquisa arrolou como tarefas primordiais da preparação para adoção o trabalho de orientação e esclarecimento dos adotantes e dos adotados acerca de questões gerais do tema.

"É a orientação e encaminhamento devido por parte de educadores, sejam de que área profissional se encontrem, mas embutido de uma especialização na área, previamente preparados para esse fim, sobre o que será a transição de uma familia original para uma familia substituta (nos casos das crianças maiores de dois anos) uma vez que essas crianças já vivenciaram a convivência com a família original, conhecem seu histórico de vida" (Assistente Social E, 61 anos).

Sobre esta questão, Weber (2001) afirma que os estereótipos e preconceitos sociais são sempre prejudiciais para as relações humanas e que no que dizem respeito à adoção é preciso enfrentá-los com conhecimento e firmeza, procurando esclarecer os fatos corretamente, divulgando dados confiáveis e debatendo com a sociedade aspectos que suscitam polêmicas e/ ou que são marcados por equívocos teóricos ou jurídicos (por exemplo, a diferença entre guarda, tutela e adoção).

Estudiosos (Weber, 2001, 2010) preocupados com a origem e os mecanismos de divulgação dos conhecimentos correntes sobre o tema da adoção, além do sistema de crenças e valores que estão na base de muitas das explicações formuladas para aplacar dúvidas e fazer estimativas futuras quanto a essa forma de vinculação socioafetiva, consideram que preparar é acima de tudo informar, levar conhecimento, divulgar experiências e pontos de vista diferentes. Para Solon (2008), a relação entre pais e filhos nesse contexto específico tende a se beneficiar de iniciativas que visem lançar luzes sobre o fenômeno da adoção em sua dimensão social, cultural e psicológica. De acordo com (Figueiredo, 2010; Solon, 2008; Weber, 2010) preparar para essa transição tão importante na infância exige o compromisso com a reprodução de informações claras e precisas sobre o que é adoção e quais os elementos e processos que lhes são constituintes.

Desconstrução de Mitos sobre a Adoção. Nesta subcategoria foram organizados conteúdos que afirmam ser a preparação infantil um trabalho que deve levar o profissional a desmontar os mitos que cercam o tema da adoção. A necessidade da desmistificação foi muito citada pelos participantes da pesquisa pelo próprio caráter que a adoção apresenta há séculos, comumente envolta em preconceitos e associada a vários ta- 
bus, provocando inquietações e sofrimento àqueles que pretendem adotar e os que desejam ter uma família, como é o caso das crianças institucionalizadas. $\mathrm{O}$ trecho a seguir lembra mitos que sempre estiveram ligados à experiência de toda e qualquer forma de adoção, mas que vêm ganhando maior visibilidade no momento em que a sociedade contemporânea debate as certezas e incertezas que se têm até o momento quanto à experiência das formas menos tradicionais de adoção cada vez mais presentes nos dias de hoje.

"Precisam ser esclarecidos de alguns pontos, como: mitos e verdades sobre adoção a revelação os tipos de adoção, mono-parentais, homo-afetivas, unilaterais, inter-raciais, tardias, etc..." (Psicóloga A, 50 anos).

Isso talvez possa estar relacionado ao fato de que o preconceito é perceptível desde os tempos antigos quando se trata de adoção e está relacionado à falta de conhecimento do que compreende essa modalidade de família. Para os autores, "Até há pouco tempo, o assunto adoção era sussurrado e não falado a plena voz pelas pessoas de nossa sociedade. Ser chamado de 'adotivo' era até ofensivo, frente ao despreparo com que o tema adoção era tratado" (CeCIF, 2002, p. 11).

A forma como essa experiência de convívio em família e vinculação socioafetiva tem sido encarada historicamente pode ser representada pelos silêncios apontados pela literatura (Gueiros, 2007; Motta, 2008; Solon, 2008; Weber, 2001, 2010) que sempre imperaram quando o assunto era adoção. Provavelmente, por isso, suas questões cruciais ficaram por muito tempo expostas a explicações míticas e formas obscuras de lidar com as dúvidas que lhe acompanham desde a sua origem e evolução em diferentes sociedades humanas.

Produto de Um Trabalho que Envolve Adotados e Adotantes. A expectativa que se cria dos dois lados que estão envolvidos no processo de adoção não pode ser descartada, uma vez que tanto o adotado quanto o adotante têm perspectiva de compor uma nova família ou laços de filiação. Com isso, no processo de adoção surgem sentimentos de ansiedade, felicidade e desejo de construir uma família, que, segundo Weber (2001), por guardarem semelhança fazem com que a preparação deva envolver necessariamente os dois lados (adotantes e adotados). "É preciso acreditar na promoção de cuidados que resguardam e projetam as famílias envolvidas na adoção, e também a criança, esse sujeito de direitos que quase sempre é deixado em segundo plano" (Weber 2010, p. 17). Alguns trechos das respostas dos participantes da pesquisa enfatizaram que a preparação precisa envolver adotantes e adotados.

"Preparação para adoção cabe tanto aos pretendentes a pais quanto a crianças $e$ adolescentes que aguardam acolhimento familiar" (Socióloga A, 59 anos).

Desse modo, a preparação infantil para a adoção deve ser vista como o resultado de um trabalho que reconhece o lugar importante ocupado pelos adultos que assumem o papel parental nesse processo (Weber, 2001), mas também reconhece de forma inovadora a centralidade do papel da criança nessa família que está em formação (Solon, 2008). Isso significa pensar que os profissionais precisam ter claro qual a concepção de família que está em questão no discurso de quem pretende adotar e igualmente de quem quer ser adotado.

A preparação para adoção representa um momento em que se deve trabalhar as idéias e expectativas que os sujeitos envolvidos têm acerca do que é viver em uma família e o que é fazer parte de uma. Nesse momento, vê-se como indispensável reforçar a noção de que essa configuração familiar não é artificial apenas porque contrasta com a forma natural de se vincular pais e filho, mas porque se trata hoje de uma modalidade de viver em família absolutamente legítima, que conta com proteção da lei e se legítima por meio dessa convivência em família, sendo este um direito garantido conforme apontam e discutem os próprios regimes jurídicos e políticas públicas (Figueiredo, 2010; MDS, 2009).

Trabalho Interdisciplinar. Durante a análise dos dados foi possível perceber que o trabalho de preparação da criança institucionalizada para adoção deve ser desencadeado no âmbito do judiciário, mas de forma simultânea e integrada com os espaços de acolhimento institucional. Neste procedimento, é imprescindível que a equipe trabalhe de forma interdisciplinar para que ocorra a interação entre os órgãos que 
concretizam a adoção: Juizado e Abrigo. As situações peculiares que cada criança apresenta devem ser trabalhadas tanto pelo espaço de acolhimento onde a criança convive diariamente, quanto pela instituição que é responsável pelos tramites legais. Alguns dos conteúdos selecionados nas respostas presentes nos questionários mostraram que este processo dinâmico e complexo tem que ser desenvolvido gradativamente, mas sempre na perspectiva da realização de um trabalho coletivo. Dessa maneira, pode ser possível pensar em uma efetiva preparação. Ou seja, preparar é envolver e integrar as equipes de trabalho que tem objetivos comuns, capacitando-as para buscar contemplar todas as demandas derivadas desse segmento e do processo adotivo como um todo.

Em relação às crianças dos abrigos, entendo que a preparação deve ser realizada pela equipe técnica do abrigo juntamente com a do Juizado da Infância, pois a partir do momento que os profissionais dos abrigos preparam o estudo da situação de uma criança ou adolescente sugerindo que o Ministério Público peça a destituição do poder familiar dos pais destes é porque chegaram à conclusão que esses já se esgotaram as possibilidades dessa criança ou adolescente permaneça nos seio de sua família de origem. (Psicóloga A, 50 anos)

\section{Propostas para a Preparação Infantil}

Esta questão foi essencial para se compreender a visão desses profissionais e como poderia ser realizado o trabalho de preparação das crianças para a vida em um lar adotivo, pois parece não existir até o momento uma metodologia padronizada, ou melhor, que se paute pelos dispositivos legais capazes de lançarem luz sobre a matéria da adoção. Dentre as categorias mais citadas, estão:

Diálogo Entre a Equipe dos Abrigos e a Equipe do Juizado. Dentre seis dos dez entrevistados, estes ratificaram que deve haver a interação, o trabalho em parceria, a participação ativa e integrada, as ações articuladas com planejamento e metodologia de trabalho comum entre as instituições envolvidas da área sociojurídica e da política de proteção social. Isso fica mais destacado no trecho da resposta dada por uma das participantes da pesquisa:

Penso que essa preparação só poderá ser realizada com diálogo entre as equipes técnicas dos abrigos e da $1^{a}$ Vara da Infância, mas com um envolvimento profissional maior na preparação das crianças maiores, que continuam nos abrigos aguardando por uma família. (Psicóloga A, 50 anos)

Em outros trechos também se percebe uma tendência a destacar a necessidade da realização de trabalhos em conjunto por parte das instituições envolvidas, de interações entre os profissionais, da troca de informações sobre o processo de adoção, ou seja, uma parceria profissional que oriente em uma mesma direção a preparação da criança para essa importante transição a ser vivida na infância. Esse trabalho em conjunto é ilustrado na publicação 101 Perguntas... (CeCIF, 2002) ao argumentar sua importância principalmente quando se trata de adoções internacionais, em que se deve envolver auxílios metodológicos para o enfrentamento das dificuldades que certamente surgirão quando se trata de crianças institucionalizadas para adotantes estrangeiros.

Acompanhamento Psicológico para as Crianças. Dois dentre os dez entrevistados alegaram haver em alguns casos a necessidade de assegurar à criança desde o início acompanhamento psicológico. Argumentam, conforme pode ser visto também na literatura (CeCIF, 2002; Weber, 2010), que a falta desse acompanhamento pode estar correlacionada a existência de adoções frustradas e mal sucedidas que muitas crianças acabam por vivenciar, permitindo que estas criem resistência que dificultam e às vezes impedem a sua inserção e completa adaptação ao novo contexto familiar.

"Nos casos em que a resistência é interna elou houve histórico de aproximação ou convivência com familia pretendente a adoção mal sucedida, é possivel que encaminhamento psicossocial seja necessário e constitua-se como parte do processo de preparação" (Pedagoga A, 29 anos).

Os acompanhamentos psicológicos são necessidades advindas de traumas, situações vivenciadas pelas crianças, que deixaram sequelas que precisam ser trabalhadas, para que estas tenham 
capacidade de aceitar e receber os pais adotivos em suas vidas. É interessante notar que alguns desses traumas estão relacionados à violência e à rejeição por sua família biológica, enquanto que outros são inerentes à rejeição sentida em uma adoção frustrada. Motta (2008) ressalta que antes de se falar sobre devoluções, situação sempre delicada para as crianças, é preciso colocar em pauta a preparação dos pais pretendentes. Para a autora, a questão da devolução revela experiências traumatizantes que atingem diretamente a autoestima da criança, sua crença de ser alguém de quem se possa gostar e a quem se possa amar.

Respeito à Voz das Crianças. Dar voz e gerar oportunidade para que as crianças possam se expressar foi um dos aspectos citados no âmbito das propostas capazes de promover a preparação para adoção. Dentre os dez, três profissionais afirmaram que há necessidade dessa compreensão para que as crianças entendam a adoção, ainda que em um nível compatível com o seu desenvolvimento. Mas, para que isso ocorra é importante utilizar recursos lúdicos conforme sua faixa etária, uma vez que dar voz às crianças é uma atitude que poderá desmistificar a própria utilização da noção de infância que ainda se faz presentes nos dias de hoje. O significado etimológico da palavra infância remete à representação daquele que não fala. Então, é preciso desconstruir esse significado que se manteve forte durante séculos para poder reconhecer que as crianças são sujeitos de direitos e, portanto, segmento que precisa ter voz e compreensão, principalmente, quando se trata da decisão de viver em família substituta. Conforme Kramer et al. (2008) é ouvir os ditos e os não ditos das crianças. Mas, infelizmente, como também reconhece Solon (2008), as crianças não têm tido muitas oportunidades de serem consultadas para falar sobre suas vidas, sendo um direito recente e contemporâneo a oportunidade de participar de decisões que envolvam sua vida, como pode ser reconhecida a adoção.

Assim, proporcionar momentos para que a pessoa adotada possa falar sobre sua história, ao longo de toda a vida, parece ser uma maneira favorável de ajudá-la no seu processo de construção de identidade (Solon, 2008, p. 155).
Para os profissionais participantes da pesquisa, é necessário proporcionar espaços em que as crianças possam expressar seus sentimentos, bem como situações de negligência que experimentaram, mas levando em consideração sua idade para que o trabalho de prepará-las esteja em sintonia e possa respeitar genuinamente o que elas tenham vivido com outras famílias (biológicas, extensas) ou em outros espaços de acolhimento. Ou seja, segundo discutem (Solon, 2008; Weber, 2010), trata-se de ser capaz de atribuir a elas o direito de participar desse processo, de serem ouvidas, de poder falar de sua própria vida, antes, durante e após a adoção.

"Na metodologia de trabalho devem estar incluídos recursos lúdicos (construção de histórias, fantoches, desenhos, etc.) de acordo com a faixa etária da criança, considerando ainda seu desenvolvimento intelectual e emocional. Deve gerar reflexões sobre sua história de vida, potencialidades, as diversas configurações de familia, além do direito a convivência e seus beneficios, apresentando a adoção como uma possibilidade de garantia desse direito. Deve ainda considerar a criança como sujeito de direitos, partícipe do seu projeto de adoção, considerando seus anseios e temores" (Assistente Social D, 44 anos).

Reflexão sobre a Família Adotiva. Estimular a reflexão da criança diante de suas expectativas em relação à família foi um dos fatores citados por quatro dentre os dez entrevistados. Seus argumentos levaram em conta a dificuldade da criança (já com algum entendimento sobre o que é família e a condição de abandono e rejeição na infância) em aceitar a nova família, bem como a edificação de novos vínculos, o afastamento de seus amigos e dos cuidadores do espaço de acolhimento institucional. Igualmente, é a idealização das crianças em relação à família adotiva, pois os profissionais alegam que essas questões todas devem ser trabalhadas com entrevistas conjuntas com as crianças e os pais adotivos, com a finalidade de explorar seus receios e temores, além de estabelecimentos de normas a serem seguidas. A seguir, um trecho da resposta dada por um dos profissionais acerca da questão em tela: 
"Poderia realizar-se através de entrevistas individuais com a criança, e entrevistas conjuntas com os futuros pais e a criança, estimulando a reflexão da criança sobre suas expectativas em relação à família com quem irá viver seus temores e esperanças em relação à nova vida sobre a familia que idealiza e a familia, adultos e crianças têm objeções e deveres, e regras a serem obedecidas" (Assistente Social A, 39 anos).

Em sua pesquisa Solon (2008) ressalta que existem vários contextos que se interligam ao processo de adoção tardia, e que as crianças, por sua vez, mostram-se impotentes diante dessas decisões tomadas pelos diferentes sujeitos (pais adotivos, técnicos e autoridades do judiciário, instituições de acolhimento), sendo que muitas delas nem compreendem o que ocorre ao longo do seu processo de adoção, devido à inexistência de informações detalhadas de como será essa nova vida em família adotiva. A autora ressalta também que, a história das relações que as crianças construíram por onde passaram se constituem em vínculos de aprendizagem, de afeto, fazem parte de suas vivências e é citado pelas próprias crianças como fator necessário.

Além disso, Solon (2008) acrescenta que as crianças ao falarem do seu processo de adoção mencionam o abrigo como um lugar de passagem e com características negativas, como esclarece uma das entrevistadas pela autora em sua pesquisa: "a adoção só acontece porque é ruim ficar no abrigo" (p. 152). Nessa perspectiva, observa-se que as crianças não têm uma reflexão sobre a família adotiva e sua história de vida não foi trabalhada, por isso entendem que devem deixar o abrigo por ser um ambiente de aspectos negativos e não por outros motivos igual ou mais importante, como por exemplo, ter uma família ou exercer o direito de convivência familiar.

Desta forma, entende-se que a criança por si só fantasia várias situações em sua vida e certamente idealiza, realçando tanto aspectos positivos como negativos, também em relação à família adotiva. Nesse momento, assim como aponta a literatura do tema (Gueiros, 2007; Motta, 2008; Solon, 2008; Weber, 2001, 2010) os profissionais consideram que deve haver atenção e dedi- cação às expectativas da criança, pois elas podem associar a família idealizada como aquela que a maltrata, ou seja, suas expectativas podem estar nos aspectos de negatividade que sofreu com a família biológica que não pôde dar ou não permitiu que esta se desenvolvesse em um ambiente acolhedor. Outro aspecto que Solon (2008) cita é que algumas crianças procuram silenciar o passado, não se sentem à vontade para falar sobre a sua vida pregressa, seja na família de origem ou na instituição em que se encontravam, o que pode representar a necessidade de trabalhar seu próprio percurso até chegar à família adotiva, procurando saber até que ponto sua trajetória de vida está comprometendo a imagem dos pretendentes à adoção e da família que está em formação a qual irá pertencer.

\section{Considerações Finais}

Os dados da pesquisa esclarecem vários aspectos no que tange a preparação de crianças para adoção. Ao analisar os dados coletados, é nítido que o trabalho não é unilateral, não pode ser operacionalizado de maneira fragmentada e assistemática pelos profissionais envolvidos no processo de adoção. Ao contrário, tem que estar em prol da interatividade coletiva entre os profissionais que trabalham com adoção. É inerente ao processo de preparação para a adoção, o trabalho com os pais adotivos e com a criança. No processo de preparação para a adoção, o lugar ocupado pela criança é central e demanda a necessidade de conectar sua história de vida, seus sentimentos e suas perspectivas em relação à família adotiva. Segundo, a preparação deve compreender a criança na centralidade da discussão, que pode se refletir em um trabalho interdisciplinar entre as instituições que operacionalizam a adoção.

Pensar na preparação e não ter em vista a criança como a protagonista da sua história, o sujeito principal deste processo, implica na fragilidade da adoção, ou seja, estar exposta a resistências que a criança possa apresentar em relação à inserção na família adotiva. Conclui-se que a preparação envolve a história de vida das crianças e uma aproximação gradativa e respeitável diante das condições emocionais e de mo- 
radia apresentadas pelo adotado. Deve-se, por isso, informar aos futuros pais adotivos que além de adotar a criança, sua história de vida também deve ser acolhida, existindo cautela em sua inserção na família substituta.

Os profissionais se dividiram ao conceituar a preparação. Para uns, requer uma parceria de trabalho entre as equipes, para outros é um processo que envolve os pais e os filhos concomitantemente, já para alguns diz respeito ao esclarecimento, a desmistificação do processo. Entretanto, poucos levaram em consideração que preparar a criança é trabalhar sua vida, sobretudo, trabalhar cada peculiaridade de seu mundo. $\mathrm{O}$ acompanhamento e a preparação são ferramentas de enfrentamento as dificuldades que podem surgir na inclusão da criança na família substituta, por consequência da história de abandono, rejeição e maus-tratos, além da questão da institucionalização prolongada que acaba interferindo no seu desenvolvimento psicossocial.

Para alguns dos profissionais entrevistados a preparação é real e para outros ainda não existe. Percebe-se que ainda não existe uma padronização nas conformidades do que propõe a Lei $n^{\circ} 12.010 / 2009$ ao elucidar que essa preparação deve existir e ser gradativa para crianças em situação de institucionalização prolongada. Baseando-se na literatura científica, conclui-se que a preparação de fato não existe, há alguns pontos que a compõem, trata-se de um conjunto de fatores e condições capazes de assegurar o envolvimento da criança e dos pais, por meio de metodologias utilizadas pelos profissionais que agem no sentido de intervir e minimizar possíveis resistências e problemas de adaptação a nova vida a outro tipo de convivência, dentre outros aspectos. Nem todos esses fatores de trabalho estão sendo ativados em conjunto, por isso há de se afirmar que essa preparação representa um processo incipiente.

Outrossim, é notório que a leitura da realidade trazida pelos sujeitos mostra que até hoje a preparação tem sido desempenhada somente pelos abrigos, sendo esta atividade recentemente assumidas pelos profissionais da $1^{\text {a }}$ Vara da Infầncia e Juventude de Belém. Este é um dos mo- tivos apresentados para aqueles que consideram que o trabalho inexiste no órgão do Judiciário, porque não havia essa determinação legal.

Deve existir nos trabalhos realizados pelas equipes tanto do Juizado como nos espaços de acolhimento uma metodologia elaborada em conjunto pelos profissionais, que envolva tanto a criança quanto os pais. Tem que haver essa ponte de ligação na elaboração de uma metodologia, de forma sistemática e metodológica para que o trabalho em prepará-las seja eficaz.

Por mais que esteja em processo de operacionalização como indicam os resultados da pesquisa, a preparação das crianças tem que estar em sintonia com uma busca por entender mais sobre este fenômeno, não devendo ser deixado para depois. Essa busca tem que ser compreendida, estudada e aprimorada. Diante das afirmações dos sujeitos sobre a existência ou não do trabalho de preparar, o desafio da equipe será o de torná-lo visível e com reflexos de desenvolvê-lo metodologicamente. Isso quer dizer que a metodologia deve ser pensada para esse fim e deverá ser responsável por tornar a realização desse trabalho viável e eficaz, envolvendo a discussão e atuação em conjunto dos profissionais que materializam a adoção no seu dia-a-dia nos seus espaços de atuação.

\section{Referências}

Andrade, R. P., Costa, N. R. A., \& Rossetti-Ferreira, M. C. (2006). Significações de paternidade adotiva: Um estudo de caso. Paidéia (Ribeirão Preto), $16(34), 241-252$.

Ayres, L. M. S., Cardoso, A. P., \& Pereira, L. C. (2009). O abrigamento e as redes de proteção para infância e a juventude. Fractal: Revista de Psicologia, 21(1), 125-136.

Beckett, C., Maughan, B., Rutter, M., Castle, J., Colvert, E., Groothues, C., ...Sonuga-Barke, E. J. S. (2006). Do the effects of early severe deprivation on cognition persist into early adolescence? Findings from the English and Romanian Adoptees Study. Child Development, 77(3), 696-711.

Cavalcante, L. I. C., \& Magalhães, C. M. C. (2012). Relações de apego no contexto da institucionalização na infância e da adoção tardia. Psicologia Argumento, 30(68), 75-85. 
Centro de Capacitação e Incentivo à Formação de Profissionais, Voluntários e Organização que Desenvolvem Trabalho de Apoio à Convivência Familiar. (Org.). (2002). 101 perguntas e respostas sobre abandono e institucionalização. São Paulo, SP: Autor.

Costa, L. F., \& Campos, N. M. V. (2003). A avaliação psicossocial no contexto da adoção: Vivências das famílias adotantes. Psicologia: Teoria e Pesquisa, 19(3), 221-230.

Figueiredo, L. C. B. (2010). Comentários à Nova Lei Nacional da Adoção. Lei 12.010 de 2009. Curitiba, PR: Juruá.

Fonsêca, C. M. S. M. S., Santos, C. P., \& Dias, C. M. S. B. (2009). Adoção de crianças com necessidades especiais. Paidéia (Ribeirão Preto), 19(44), 303-311.

Gueiros, D. A. (2007). Adoção consentida: Do desenraizamento social da família à prática de adoção aberta. São Paulo, SP: Cortez.

Kramer, S., Barbosa, S. N. F., \& Silva, J. P. (2008). Questões teórico-metodológicas da pesquisa com crianças. In H. V. C. Silva (Org.), A criança fala: A escuta de crianças em pesquisas (pp. 79-101). São Paulo, SP: Cortez.

Lei $n^{\circ} 8.069$, de 13 de julho de 1990. (1990, 16 jul.). Dispõe sobre o Estatuto da Criança e do Adolescente e dá outras providências. Diário Oficial da União. Recuperado em http://www.planalto. gov.br/ccivil_03/leis/18069.htm

Lei $\mathrm{n}^{\circ}$ 12.010/2009, de 3 de agosto de 2009. (2009, 04 ago.). Dispõe sobre adoção; altera as Leis $\mathrm{n}^{\text {os }} 8.069$, de 13 de julho de 1990 - Estatuto da Criança e do Adolescente, 8.560, de 29 de dezembro de 1992; revoga dispositivos da Lei ${ }^{\circ}$ 10.406, de 10 de janeiro de 2002 - Código Civil, e da Consolidação das Leis do Trabalho - CLT, aprovada pelo Decreto-Lei $n^{\circ} 5.452$, de $1^{\circ}$ de maio de 1943; e dá outras providências. Diário Oficial da União. Recuperado em http://www. planalto.gov.br/ccivil_03/_ato2007-2010/2009/ lei/112010.htm

Mariano, F. N., \& Rossetti-Ferreira, M. C. (2008). Que perfil da família biológica e da adotante, e da criança adotada revelam os processos judiciais? Psicologia: Reflexão e Crítica, 21(1), 11-19.
McGuire, S., \& Shanahan, L. (2010). Sibling experiences in diverse family contexts. Social Development Perspectives, 2, 72-79.

Ministério do Desenvolvimento Social e Combate à Fome. (2006). Plano nacional de promoção, proteção e defesa do direito da criança e do adolescente à convivência familiar e comunitária. Brasília, DF: Autor.

Ministério do Desenvolvimento Social e Combate à Fome. (2009). Orientações técnicas para Serviços de acolhimento de crianças e adolescentes. Brasília, DF: Autor.

Motta, M. A. P. (2008). Mães abandonadas: A entrega de um filho em adoção. São Paulo, SP: Cortez.

Pontes, M. L. C., Cabrera, J. C., Ferreira, M. C., \& Vaisberg, M. J. A. (2008). Adoção e exclusão insidiosa: $\mathrm{O}$ imaginário de professores sobre a criança adotiva. Psicologia em Estudo (Maringá), 13(3), 495-502.

Serrano, S. A. (2008). O abrigamento de crianças de zero a seis anos de idade em Ribeirão Preto: Caracterizando esse contexto (Tese de doutorado, Faculdade de Filosofia, Ciências e Letras, Universidade de São Paulo, Ribeirão Preto, SP, Brasil).

Solon, L. A. G. (2008). Conversando com crianças sobre adoção. São Paulo, SP: Casa do Psicólogo.

Weber, L. N. D. (2001). Aspectos psicológicos da adoção. Curitiba, PR: Juruá.

Weber, L. N. D. (2010). Pais e filhos por adoção no Brasil: Características, expectativas e sentimentos. Curitiba, PR: Juruá.

Zeanah, C. H., Smyke, A. T., \& Koga, S. F. (2005). Attachment in institucionalized and community children in Romania. Child Development, 76(5), 1015-1028. 